rückzuführen ist. Die hierüber angestellten Versuche sind noch nicht abgeschlossen.

Der Osram-Studiengesellschaft, Berlin, danken wir für die uns zur Verfügung gestellte HNS 12 und das UV-Normal.

Besonderer Dank gilt auch der D e u t s c he n F or $\mathrm{sch} u \mathrm{~g} \mathrm{sg}$ e m e in s chaf $\mathrm{t}$ für die Unterstützung der Arbeit.

A n m. b. d. K o r r. : In der Zwischenzeit erhielten wir eine weitere Arbeit ${ }^{9}$, die sich mit der Latenzzeit-Verlängerung uv-bestrahlter Tl-Phagen befaßt. Die Bestrahlung der Phagen wurde von SETLOw und Mitarbb. mit vakuumgetrocknetem Material bei Zimmertemperatur und der Temperatur von flüssiger Luft durchgeführt. Es wird die Verlängerung der Latenzzeit als dosisproportional beschrieben (vgl. EскаRт $^{8}$ ) sowie über eine Photoreaktivierung und das Wirkungsspektrum dieser Schädigung berichtet. Ein Vergleich der Ergebnisse mit den eigenen Befunden wird dadurch erschwert, daß eine andere Versuchsmethodik und eine andere Definition der Latenzzeit verwendet wird.

9 R. Setlow, S. Robbins u. E. Polard, Radiation Res. 2, 262 [1955].

\title{
Tridhloressigsäure-Aceton-Extraktion von Albuminen aus Seren und Antigen-Antikörper-Präzipitaten
}

\author{
Von Ekkehard Kallee, Friedrich Lohss und Willmar OppermanN* \\ Aus der Medizinischen Universitätsklinik Tübingen (Direktor: Prof. Dr. H. Bennhold) \\ (Z. Naturforschg. 12 b, 777-783 [1957]; eingegangen am 20. August 1957)
}

\begin{abstract}
1. Highly purified albumin fractions can be obtained by precipitating human, rabbit, or rat sera with trichloroacetic acid, and extracting the precipitates with acetone.

2. Human albumin thus prepared is identical with the original albumin in its electrophoretic properties, its dye-binding ability, and in its immunological behavior.

3. After precipitating human albumin with antibodies the albumin antigen can be extracted in a good yield by use of trichloroacetic acid and acetone without losing the electrophoretic or antigenic characteristics of albumin.
\end{abstract}

Trichloressigsäure (= TCA) wird seit langem zur routinemäßigen Enteiweißung von proteinhaltigen Lösungen verwendet. Man hatte bisher allgemein angenommen, daß die TCA-Fällung aller Proteine ausgenommen Insulin ${ }^{1}$ - eine irreversible Denaturierung darstelle. Um so bemerkenswerter erschien uns daher eine Mitteilung von Schwert ${ }^{2}$, der Rinderalbumin mit TCA gefällt und das Präzipitat in Aceton (=Ac) gelöst hatte; nach der Dialyse dieser TCA - Ac-Albuminlösungen konnte er in hoher Ausbeute ein Rinderalbumin erhalten, das in seiner Sedimentationskonstante, elektrophoretischen Beweglichkeit, Löslichkeit und Kristallisierbarkeit mit dem unbehandelten Albumin identisch war. In Anbetracht der praktischen Bedeutung dieser Befunde schien es uns wichtig zu prüfen, ob diese überaus einfache Methode allgemein zur Reindarstellung von Serum-Albuminen dienen könnte. Wir unternahmen deshalb Versuche zur Extraktion von Albumin aus den TCA-Präzipitaten von Human-, Kaninchen- und Rattenseren. Die gewonnenen Albuminfraktionen wurden papierelektrophoretisch untersucht; ferner

\footnotetext{
* Ass.-Arzt am Robert-Bosch-Krankenhaus Stuttgart (Chefarzt: Doz. Dr. G. Seyвold), derzeit Gastarzt im Isotopenlabor der Med. Klinik Tübingen.
}

verglichen wir das Farbstoff-Bindungsvermögen von Human-Serum-Albumin (HSA) mit TCA-HSA. Schließlich führten wir immunbiologische Versuche mit HSA und TCA-Albumin durch, teilweise unter Verwendung von ${ }^{131} \mathrm{~J}$ - HSA. Es zeigte sich, daß die TCA - Ac-Extraktionsmethode offenbar ganz allgemein dazu geeignet ist, Albumine von Globulinen zu trennen, nicht nur aus verschiedenen Seren, sondern auch aus Immunpräzipitaten.

\section{Versuchsergebnisse}

I. TCA-Albumin-Extrakte aus Seren

1. Mischelektrophoresen von dialysiertem TCAAc-HSA mit dem als Ausgangsmaterial dienenden HSA (Behringwerke) ergaben keinen Anhaltspunkt für eine Änderung der papierelektrophoretischen Beweglichkeit des TCA - Ac - HSA. Dialysierte TCA Ac-Extrakte aus Human-Mischserum lieferten praktisch globulinfreies HSA (Abb. 1). Die auf dem Elektrophorese-Streifen (B) erkennbare Anfärbung im Globulinbereich ist nicht durch Globulin-Verun-

\footnotetext{
1 C. Bомsкоv, „Methodik der Hormonforschung“, Vol. I, 673, G. Thieme Verlag, Leipzig 1937.

2 G. W. Schwert, J. Amer. chem. Soc. 79, 139 [1957].
} 
reinigungen verursacht, sondern durch eine Adsorption von Albumin an das Filtrierpapier ${ }^{3}$; jedenfalls sind keine Banden erkennbar, die irgendeinem Globulin entsprechen könnten.

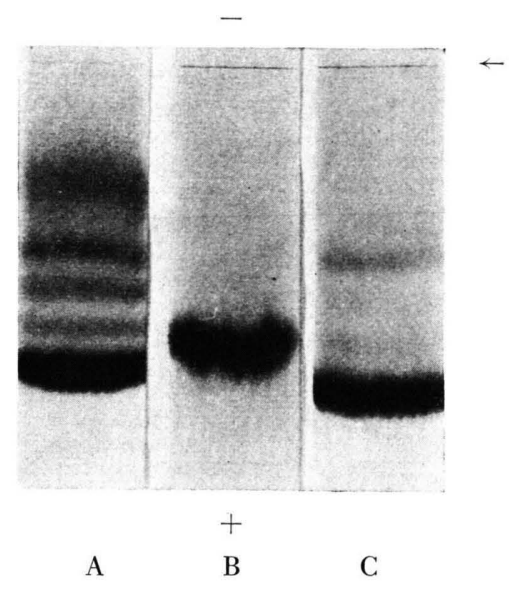

Abb. 1. Papierelektrophoresen von Humanmischserum vor und nach TCA-Behandlung und anschließender Extraktion. A: $\quad 0,008 \mathrm{~cm}^{3}$ Humanmischserum vor TCA-Behandlung, $6,8 \mathrm{~g}-\%$ Protein enthaltend. B: $0,01 \mathrm{~cm}^{3}$ TCA-Ac-Extrakt des gleichen Serums, $2,5 \mathrm{~g}$-\% Protein enthaltend. C: $0,01 \mathrm{~cm}^{3}$ TCA - $\mathrm{NaHCO}_{3}$-Extrakt des gleichen Serums, 3,3 g-\% Protein enthaltend. Auf dem Streifen B läßt sich außer Albumin keine weitere Serumprotein-Fraktion erkennen, auf dem Streifen C sind $\beta$ - und $\alpha_{1}$-Globuline deutlich zu sehen, $\alpha_{2}$-Globulin nur angedeutet. Die unterschiedliche Wanderstrecke hat nichts mit einer Änderung der elektrophoretischen Beweglichkeit der Albumine zu tun, was durch Abb. 5 bewiesen wird. Whatman I-Papier; Elphor (Bender \& Hobein, München); $110 \mathrm{~V}$; $p_{\mathrm{H}} 8,5$; Veronal-Na-acetat-Puffer; $\mu=0,1$; Amidoschwarz

10 B. $\downarrow=$ Auftragestellen, $+=$ Anode, $-=$ Kathode.

TCA - Ac-Extrakte aus Kaninchen- bzw. Rattenserum lieferten ebenfalls praktisch globulinfreie Albumine (Abb. 2).

2. Aus TCA-Präzipitaten von Humanserum läßt sich nicht nur mit organischen Lösungsmitteln wie $\mathrm{Ac}^{2}$ oder Alkoholen ${ }^{2,4-6}$ HSA extrahieren, vielmehr genügt hierfür auch eine Neutralisation der TCA mit $\mathrm{NaHCO}_{3}$. Allerdings sind solche $\mathrm{NaHCO}_{3}$-Extrakte lediglich frei von $\gamma$-Globulinen, während - im Gegensatz zur Ac-Extraktion - $\beta$ und $\alpha$-Globuline noch in deutlich nachweisbaren Mengen mit in Lösung gehen (Abb. 1, C). Dieser Befund zeigt, daß durch eine Fällung mit 5-proz. TCA selbst die empfindlicheren $\alpha$ - und $\beta$-Globuline nicht vollständig denaturiert werden.

${ }^{3}$ H. Bennhold, E. Kallee u. E. Roth, Z. Naturforschg. 7 b, 324 [1952].

4 S. Levine, Arch. Biochem. Biophysics 50, 515 [1954].
Mit 5-proz. neutralem TCA-Na konnte aus Humanmischserum kein Protein gefällt werden. Daraus ist abzuleiten, daß das Trichloracetat-Ion allein keine $\gamma$-Globuline fällt; vielmehr ist für die Denaturierung von $\gamma$-Globulinen durch TCA ein niedriger $p_{\mathrm{H}}$-Wert erforderlich.

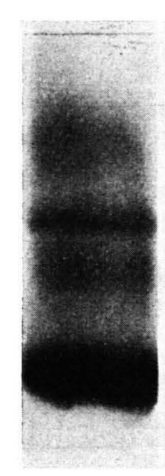

A

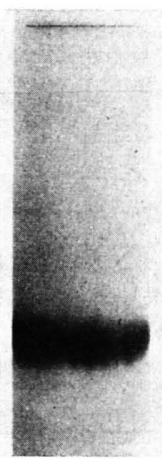

B

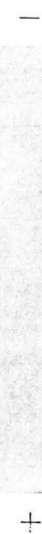

$+$
Abb. 2. Gewinnung von Kaninchen- und Rattenalbumin durch TCA-Ac-Extraktion. A: $0,008 \mathrm{~cm}^{3}$ Kaninchen-Mischserum, vor TCA-Ac-Extraktion, 6,6 g-\% Protein enthaltend. B: $0,01 \mathrm{~cm}^{3}$ TCA - Ac-Extrakt des gleichen Serums, 3 g-\% Protein enthaltend. C: $0,008 \mathrm{~cm}^{3}$ Rattenserum, vor TCAExtraktion, $8,0 \mathrm{~g}-\%$ Protein enthaltend. D: $0,01 \mathrm{~cm}^{3}$ TCA Ac-Extrakt des gleichen Serums, ca. 4 g-\% Protein enthaltend. Außer Albumin sind keine Globulinspuren zu erkennen. Die mit dem Albumin von Streifen C fast identische Wanderstrecke des TCA-Albumins auf diesem Streifen ist zufallsbedingt.

3. Die Albumin-Ausbeuten, berechnet auf die dialysierten TCA - Ac-Extrakte vor der Pervaporation, sind überraschend hoch. Nach einmaliger TCA - Ac-Extraktion von HSA aus Mischserum betrug die Ausbeute ca. $71 \%$ des eingesetzten Albumins; die entsprechenden Werte bei Kaninchen- bzw. Rattenserum waren ca. $68 \%$ bzw. $72 \%$, lagen also durchschnittlich um 70 Prozent. (In späteren Versuchen betrugen die Ausbeuten bei Humanserum ca. 76 und $90 \%$, bei Kaninchenserum ca. $100 \%$, bei Rattenserum ca. 80 und $100 \%$.)

Noch höher war die HSA-Ausbeute nach der Neutralisierung der TCA mit $\mathrm{NaHCO}_{3}$, nämlich 95\%, was praktisch einer quantitativen Wiedergewinnung entspricht; jedoch findet man bei diesem Neutralisationsverfahren neben Albumin noch etwa $15 \% \alpha$ und $\beta$-Globulin-Verunreinigungen (Tab. 1).

\footnotetext{
5 M. Delaville, G. Delaville u. J. Delaville, Ann. pharmac. franc. 12, 109 [1954], zit. n. SCHWERT ${ }^{2}$.

${ }^{6}$ A. Korner u. J. R. Debro, Nature [London] 178, 106i [1956].
} 


\begin{tabular}{|c|c|c|c|c|c|c|c|}
\hline $\begin{array}{l}\text { Art des } \\
\text { Serums }\end{array}$ & Fraktion & $\begin{array}{l}\text { mg Eiweiß } \\
\text { vor Ex- } \\
\text { traktion }\end{array}$ & $\begin{array}{l}\text { in \% der } \\
\text { Gesamt- } \\
\text { proteine vor } \\
\text { der Fällung }\end{array}$ & $\begin{array}{c}\text { mg Eiweiß } \\
\text { nach Ex- } \\
\text { traktion }\end{array}$ & $\begin{array}{l}\text { in } \% \text { der } \\
\text { Gesamt- } \\
\text { proteine } \\
\text { nach der } \\
\text { Fällung }\end{array}$ & $\begin{array}{l}\text { Ausbeute } \\
\text { in \% der } \\
\text { Fraktion }\end{array}$ & $\begin{array}{c}\text { Extraktions- } \\
\text { mittel }\end{array}$ \\
\hline $\begin{array}{l}\text { Human- } \\
\text { Misch- } \\
\text { serum }\end{array}$ & $\begin{array}{l}\text { Gesamt- } \\
\text { proteine } \\
\text { Albumin } \\
\alpha_{1} \text {-Glob. } \\
\alpha_{2} \text {-Glob. } \\
\beta \text {-Glob. } \\
\gamma \text {-Glob. }\end{array}$ & $\begin{array}{r}684 \\
309 \\
40 \\
63 \\
108 \\
165\end{array}$ & $\begin{array}{r}100 \\
45,1 \\
5,8 \\
9,2 \\
15,8 \\
24,2\end{array}$ & $\begin{array}{r}268 \\
220 \\
\text { ca. } 0 \\
0 \\
0 \\
0\end{array}$ & $\begin{array}{r}100 \\
82 \\
\text { ca. } 0 \\
0 \\
0 \\
0\end{array}$ & $\begin{array}{r}39 \\
71 \\
\text { ca. } 0 \\
0 \\
0 \\
0\end{array}$ & Aceton \\
\hline dto. & $\begin{array}{l}\text { Gesamt- } \\
\text { Proteine } \\
\text { Albumin } \\
\alpha_{1} \text {-Glob. } \\
\alpha_{2} \text {-Glob. } \\
\beta \text {-Glob. } \\
\gamma \text {-Glob. }\end{array}$ & $\begin{array}{r}684 \\
309 \\
40 \\
63 \\
108 \\
165\end{array}$ & $\begin{array}{r}100 \\
45,1 \\
5,8 \\
9,2 \\
15,8 \\
24,2\end{array}$ & $\begin{array}{r}355 \\
296 \\
15 \\
9 \\
28 \\
0\end{array}$ & $\begin{aligned} 100 \\
83 \\
\text { ca. } 4 \\
\text { ca. } 2,5 \\
8 \\
0\end{aligned}$ & $\begin{array}{r}52 \\
\mathbf{9 5} \\
37 \\
14 \\
26 \\
0\end{array}$ & $\mathrm{NaHCO}_{3}$ \\
\hline $\begin{array}{l}\text { Kanin- } \\
\text { chen- } \\
\text { Misch- } \\
\text { serum }\end{array}$ & $\begin{array}{l}\text { Gesamt- } \\
\text { proteine } \\
\text { Albumin } \\
\alpha \text {-Glob. } \\
\beta \text {-Glob. } \\
\gamma \text {-Glob. }\end{array}$ & $\begin{array}{r}665 \\
354 \\
102 \\
93 \\
116\end{array}$ & $\begin{array}{r}100 \\
53,3 \\
15,3 \\
14,0 \\
17,5\end{array}$ & $\begin{array}{r}267 \\
240 \\
\text { ca. } 0 \\
0 \\
0\end{array}$ & $\begin{array}{r}100 \\
90 \\
\text { ca. } 0 \\
0 \\
0\end{array}$ & $\begin{array}{r}40 \\
\mathbf{6 8} \\
\text { ca. } 0 \\
0 \\
0\end{array}$ & Aceton \\
\hline $\begin{array}{l}\text { Ratten- } \\
\text { serum }\end{array}$ & $\begin{array}{l}\text { Gesamt- } \\
\text { proteine } \\
\text { Albumin } \\
\alpha_{1} \text {-Glob. } \\
\alpha_{2} \text {-Glob. } \\
\beta \text {-Glob. } \\
\gamma \text {-Glob. }\end{array}$ & $\begin{array}{r}159 \\
64 \\
27 \\
8 \\
29 \\
31\end{array}$ & $\begin{array}{c}100 \\
41,2 \\
17 \\
5,4 \\
17,4 \\
18,6\end{array}$ & $\begin{array}{r}52 \\
46 \\
\text { ca. } 0 \\
0 \\
0 \\
0\end{array}$ & $\begin{array}{c}100 \\
88,5 \\
\text { ca. } 0 \\
0 \\
0 \\
0\end{array}$ & $\begin{array}{r}33 \\
72 \\
\text { ca. } 0 \\
0 \\
0 \\
0\end{array}$ & Aceton \\
\hline
\end{tabular}

Tab. 1. Ausbeuten an Proteinfraktionen bei TCA-Fällungen von verschiedenen Blutseren und nachfolgender Extraktion. „ca. 0 “ bedeutet, daß durch die adsorptive Schwanzbildung der Albumine etwaige Globulinspuren verschleiert bleiben können.

4. Versuche, auch noch andere Proteine durch TCA-Fällung und Extraktion mit organischen Lösungsmitteln zu gewinnen oder wenigstens zu reinigen, schlugen fehl. Weder ein farbstoffbindendes Protein mit $\beta$-Globulinbeweglichkeit aus wäßrigen Extrakten von Mitochondrien ${ }^{7}$ noch ein solches aus flüssigem Cytoplasma von Rattenlebern ${ }^{8}$ konnte mit TCA - Ac, TCA - Äthanol bzw. TCA - $\mathrm{NaHCO}_{3}$ gewonnen werden. Auch Bence-Jones-Protein blieb unlöslich.

\section{Farbstoffbindung von TCA-HSA}

Da schon lange bekannt ist, daß gereinigte HSAPräparate ein geringeres Farbstoff-Bindungsvermögen besitzen als natives $\mathrm{HSA}^{9}$, und daß Serum-

7 E. Kallee, Arch. Biochem. Biophysics 60, 265 [1956].

8 W. Oppermann u. E. Kallee, in Vorbereitung.

9 H. Bennhold, H. Отt u. E. Kallee, Hoppe-Seyler's Z. physiol. Chem. 287, 185 [1951].

10 T. Kusunoki u. H. Kimura, J. Biochemistry [Tokyo] 42, 111 [1955].
Albumine ihre Farbstoff-Bindungsfähigkeit bei enzymatischer Verdauung verlieren ${ }^{10}$, versuchten wir mit Gleichgewichtsdialysen festzustellen, ob TCA HSA seine Bindungsfähigkeit für Bromphenolblau im Vergleich zum Original-HSA ändert. Wir benutzten dafür teilweise die klassische Gleichgewichtsdialyse $^{11,12 a}$ gegen Pufferlösungen. Für einige andere Versuche wandten wir aber auch ein neues Verfahren an, bei dem die Flüssigkeiten außerhalb und innerhalb der Dialysemembran dieselben Proteinund Farbstoffkonzentrationen enthalten ${ }^{8}$; ist die Farbstoff-Bindungsfähigkeit des Proteins auf der einen Seite der Membran größer als die des Proteins auf der anderen Seite, so muß das stärker bindende Protein infolge der Konkurrenzadsorption

11 I. M. Kцотz, Cold Spring Harbor Sympos. quantitat. Biol. 14, 97 [1949] (Übersichtsreferat).

12 a W. Oppermane u. H. Отt, Hoppe-Seyler's Z. physiol. Chem. 308, 43 [1957]. 
mehr Farbstoff aufnehmen als das schwächer bindende Protein. In einem solchen Falle müßte das Verhältnis der Farbstoffkonzentrationen innerhalb und außerhalb der Membran $\left(R_{\mathrm{i} / \mathrm{a}}\right)$ größer oder kleiner als 1,0 werden.

Bei der „klassischen“ Dialysemethode lagen die Unterschiede zwischen HSA und TCA - HSA innerhalb der Fehlerbreite (Tab. 2). Auch in den „Konkurrenz"-Dialysen war die Bindungsfähigkeit des TCA - HSA nicht erniedrigt, eher erhöht; trotz einer statistischen Signifikanz von $5 \sigma_{\text {Diff. }}$ möchten wir aus dem geringen Unterschied $(7 \%)$ keinen verbindlichen Schluß ziehen (Tab. 3). Es wäre allerdings denkbar, daß die Bindungsfähigkeit von TCA - HSA gegenüber anionischen Farbstoffen durch solche Bindungsplätze erhöht wird, die vor der Ac-Extraktion durch Fettsäuren ${ }^{12 b}$ belegt waren.

\begin{tabular}{|c|c|r|c|}
\hline $\begin{array}{c}\text { BPB-Zusatz } \\
\text { (außen) } \\
{[\mathrm{mg} \%]}\end{array}$ & \multicolumn{3}{|c|}{$\mathrm{mg \%}$ freies Bromphenolblau in: } \\
\cline { 2 - 4 } & $\begin{array}{c}\text { Human- } \\
\text { Mischserum }\end{array}$ & HSA & TCA-HSA \\
10 & $\begin{array}{r}2,6 \\
8,8\end{array}$ & $\begin{array}{r}5,6 \\
13,6\end{array}$ & $\begin{array}{r}6,3 \\
11,2\end{array}$ \\
30 & 13,6 & 13,2 & 11,6 \\
\hline $\begin{array}{c}\text { Regressions- } \\
\text { koeffizienten }\end{array}$ & 0,6 & 0,6 & 0,5 \\
\hline
\end{tabular}

Tab. 2. „Klassische“ Gleichgewichtsdialysen von 1-proz., gegen Tyrodelösung erschöpfend dialysierten Proteinlösungen. Innenflüssigkeit: $3,0 \mathrm{~cm}^{3}$ Proteinlösung, Außenflüssigkeit: $15 \mathrm{~cm}^{3}$ Tyrodelösung (ohne Glucose). Das Dialysegleichgewicht für BPB war bei $4^{\circ} \mathrm{C}$ innerhalb $48 \mathrm{Stdn}$. eingestellt.

Die gemessenen Werte liegen innerhalb der bei Dialysen unumgänglichen Fehlerbreite der Methode.

\begin{tabular}{|c|c|c|}
\hline Innenflüssigkeit & Außenflüssigkeit & $R_{\mathrm{i} / \mathrm{a}}$ \\
\hline TCA-HSA & HSA & $1,07 \pm 0,04$ \\
HSA & TCA-HSA & $0,96 \pm 0,10$ \\
\hline
\end{tabular}

Tab. 3. „Konkurrenz“-Dialyse von Bromphenolblau gegen HSA und TCA - HSA. Die Dialyse-Ansätze enthielten innen und außen jeweils $1 \%$ Protein und $0,02 \%$ Bromphenolblau in Veronalpuffer $p_{\mathrm{H}} 8,5 . R_{\mathrm{i} / \mathrm{a}}$ gibt das Verhältnis zwischen der Farbstoffkonzentration innerhalb der Dialysemembran und außerhalb der Membran an. Die Ansätze wurden 3 Tage lang bei $4-6^{\circ} \mathrm{C}$ unter ständigem Umwälzen dialysiert (2 Umwälzungen/min.). Es ist aus der Tabelle ersichtlich, daß die Werte um 1,0 liegen und sich damit innerhalb der Fehlerbreite der Methode bewegen.

12 b U. Westphal, J. F. Stets u. S. G. Priest, Arch. Biochem. Biophysics 43, 463 [1953].

13 Zusammenfassung bei P. L. Carpenter, Immunology and Serology, W. B.Saunders Company, Philadelphia and London 1956.
III. Immunbiologische Versuche mit T C A - HSA

1. Außer dem vollständigen oder teilweisen Verlust seiner charakteristischen Löslichkeit ändern sich bei der Denaturierung eines Plasmaproteins durch Hitze, Säuren oder Alkalien häufig auch seine antigenen Eigenschaften ${ }^{13}$.

Nachdem schon Korner und Debro ${ }^{6}$ in qualitativen, orientierenden Versuchen ein TCA-Rattenalbumin mit homologem Antikörper (= AK) gefällt hatten, schien uns eine quantitative immunologische Prüfung des mit TCA behandelten Albumins wichtig. Wir verglichen es mit HSA der Behringwerke (Abb. 3).

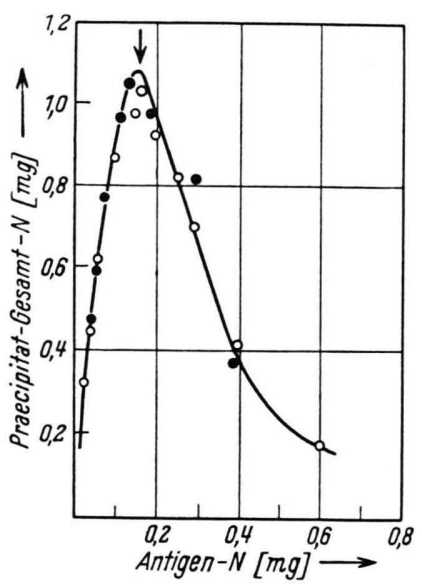

Abb. 3. Quantitative Präzipitinreaktion von Kaninchen-Antiserum gegen HSA mit homologem HSA-Antigen $(O)$ und TCA-Albumin $(\bullet)$.

Die Abb. 3 zeigt die quantitative Präzipitinreaktion von Antiserum gegenüber HSA mit seinem homologen Antigen (=AG). Die Kurve fällt im Bereich des Antigenüberschusses steil gegen den 0-Punkt ab. Dies spricht nach CoHN ${ }^{14}$ ebenso für eine einheitliche AG-AK-Reaktion wie die Tatsache, daß wir in den Überständen der einzelnen Versuche bei qualitativen Testen AG und AK nie nebeneinander fanden ${ }^{15}$. Wie aus Abb. 3 ersichtlich ist, konnten wir keine qualitativen oder quantitativen Unterschiede zwischen der Präzipitinreaktion von HSA und dem daraus hergestellten TCA-Albumin feststellen.

14 M. Cohn, L. R. Wetter u. H. F. Deutsch, J. Immunology 61, 283 [1949].

15 F. E. Kendall, J. clin. Invest. 16, 921 [1937]. 
Wir hatten 3 Kaninchen mit alaunpräzipitiertem TCA-Albumin immunisiert; alle 3 Tiere zeigten eine durch Präzipitinreaktion deutlich nachweisbare AKBildung. Der Kurvenverlauf der quantitativen Präzipitinreaktion des Antiserums mit dem besten Titer gegen TCA-Albumin ist aus Abb. 4 ersichtlich. HSA zeigt mit demselben Serum keine andere Reaktion.

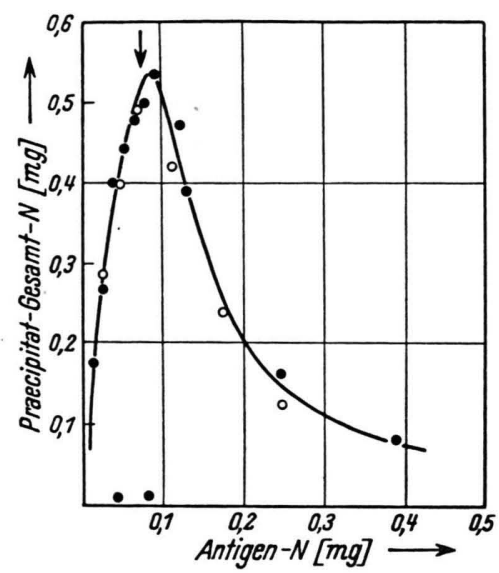

Abb. 4. Quantitative Präzipitinreaktion von Kaninchen-Antiserum gegen Human - TCA-Albumin mit homologem Antigen (•) und HSA (O). Die beiden an der Abszisse eingezeichneten Punkte demonstrieren die fehlende Präzipitinreaktion mit homologem TCA-Antigen nach Absättigung der Antikörper durch HSA.

Auch die Werte $R \frac{\text { Antikörper max. }}{\text { Antigen }}$ sind bei den Kurvenverläufen der Abb. 3 und Abb. 4 dieselben. Nach erschöpfender Absättigung des Antiserums durch HSA mit TCA-Albumin konnte keine Präzipitinreaktion mehr erzielt werden. Die Versuche beweisen somit, daß menschliches TCA-Albumin dieselben immunologischen Eigenschaften besitzt wie HSA und auch keine zusätzlich neue Antigeneigenschaft annimmt.

2. Nachdem durch die eingangs beschriebenen Versuche (I, 1.) klargestellt war, daß mittels der TCA - Ac-Extraktion globulinfreies Albumin gewonnen werden kann, interessierte uns die Frage, ob sich auch aus Albumin-Antialbumin-Präzipitaten das AG freisetzen ließe. Wir fanden tatsächlich, daß aus solchen AG - AK-Präzipitaten das reine Albumin großenteils wiedergewonnen werden kann (Abb. 5). Ob sich der AK durch TCA-Ac-Extraktion vollständig vom AG befreien läßt, kann aus unseren Versuchen nicht mit Sicherheit abgeleitet werden, da wir keine erschöpfenden Extraktionen durchgeführt haben.

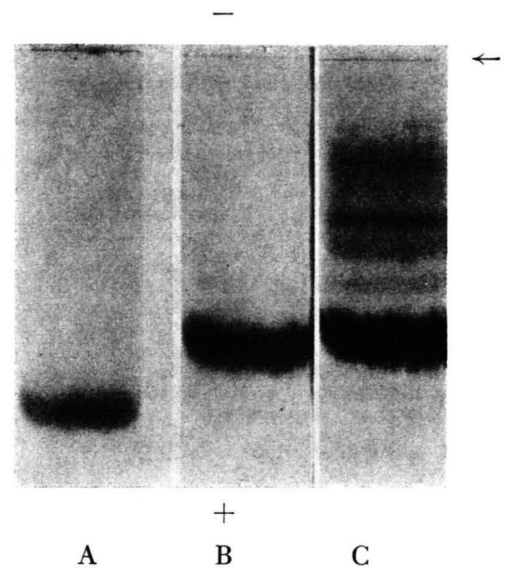

Abb. 5. Papierelektrophoresen von TCA-Ac-Extrakten aus ${ }^{131} \mathrm{~J}-\mathrm{HSA}-\mathrm{AG}-\mathrm{AK}$-Präzipitaten. A: $0,02 \mathrm{~cm}^{3}$ dialysierter und mit Hilfe von Dextranbrei eingeengter TCA-Ac-Extrakt eines ${ }^{131} \mathrm{~J}-\mathrm{HSA}-\mathrm{AG}$ - AK-Präzipitats. Das zurückgewonnene ${ }^{131} \mathrm{~J}$-Albumin ist frei von Globulinen, enthält also keinerlei AK-Spuren. (Färbung mit Amidoschwarz 10 B.) B: Zum Streifen $C$ gehörige Autoradiographie. Die radioaktive Bande deckt sich genau mit der Albuminbande von HumanMischserum (C). C: $0,02 \mathrm{~cm}^{3}$ nichtradioaktives Human-Mischserum mit ca. $0,01 \mathrm{~cm}^{3}$ radioaktivem TCA-Ac-Extrakt von (A) gemischt. $0,01 \mathrm{~cm}^{3}$ dieses ungefähr $4-5 \mathrm{~g}$-\% Protein enthaltenden Gemisches aufgetragen. Färbung vor der Anfertigung des Autoradiogramms.

Jedoch fanden wir, daß ein mit TCA - Ac aus dem AG-AK-Präzipitat extrahiertes ${ }^{131} \mathrm{~J}$-Humanalbumin bei der zweiten Fällung mit Hilfe von Antihumanalbumin-Kaninchenserum praktisch vollständig gefällt werden kann. Damit ist durch eine Kombination von TCA - Ac-Extraktion und AK-Präzipitation offensichtlich eine hochspezifische Reinigung von antigenem Albumin möglich.

Die Tab. 4 zeigt, daß etwa $18-30 \%$ des eingesetzten ${ }^{131} \mathrm{~J}$-HSA nach zwei- bis dreimaliger TCA - Ac-Extraktion am AK haften bleiben. Das bedeutet, daß mindestens $70-82 \%$ des $A G$ bei diesem Vorgehen vom AK-Präzipitat abgetrennt werden können. Die effektive, d. h. die für weitere Versuche zur Verfügung stehende, Ausbeute an AG betrug nach der ersten AG - AK-Präzipitation und anschließenden TCA - Ac-Extraktion jedoch nur etwa 38 bis 57\% ${ }^{131} \mathrm{~J}$-HSA. Diese "effektive“ Ausbeute erhöht sich theoretisch noch um den Betrag, den die unvermeidlichen Verluste während der zahlreichen Arbeitsgänge bei Verwendung von höchstens 1,0 bis $1,5 \mathrm{mg}{ }^{131} \mathrm{~J}$ - HSA ausmachen.

Je nach Reinheitsgrad des HSA oder dem Verhältnis AG : AK wurden bei der ersten AG - AK-Präzipitation 
$4-26 \%$ des AG überhaupt nicht erfaßt, sondern blieben im AK-Überstand; kleinere Anteile $(1-3 \%)$ blieben in den zu den häufigen Waschungen verwendeten $\mathrm{NaCl}$-Lösungen gelöst, ein anderer Teil blieb in den Dialysierschläuchen hängen $(1,4-14 \%)$; geringe Mengen wurden an die verwendeten Glasgeräte (Pipetten usw.) adsorbiert. Jedenfalls fanden wir im Durchschnitt nur $90 \%$ der zur ersten AG - AK-Reaktion eingesetzten ${ }^{131} \mathrm{~J}$ - HSA-Radioaktivität bilanzmäßig wieder.

\begin{tabular}{|l|c|c|}
\hline & $\begin{array}{c}\text { Mittel- } \\
\text { wert } \\
{[\%]}\end{array}$ & $\begin{array}{c}\text { Schwan- } \\
\text { kungs- } \\
\text { bereich } \\
{[\%]}\end{array}$ \\
\hline $\begin{array}{l}\text { Erste } A G-A K \text {-Fällung: } \\
\text { (4 Versuche) }\end{array}$ & & \\
$\begin{array}{l}\text { Aus dem AK-Präzipitat nicht } \\
\text { extrahierbare AG-Reste }\end{array}$ & $\mathbf{2 3 , 2}$ & $18-30$ \\
$\begin{array}{l}\text { AG-Verluste durch Manipula- } \\
\text { tionen, soweit erfaßbar }\end{array}$ & 22,4 & $12-30$ \\
$\begin{array}{l}\text { Effektive AG-Ausbeute nach } \\
\text { TCA-Ac-Extraktion }\end{array}$ & $\mathbf{4 4 , 7}$ & $38-57$ \\
$\begin{array}{l}\text { Insgesamt wiedergefunden } \\
\text { Zweite AG-AK-Fällung: } \\
\text { (2 Versuche) }\end{array}$ & 90,3 & $87,0-93,6$ \\
$\begin{array}{l}\text { AG-Verluste im AK-Über- } \\
\text { stand, incl. NaCl-Überstände } \\
\text { von 3 Waschungen } \\
\text { AG-Ausbeute aus dem in } \\
\text {-NaOH gelösten AG-AK- }\end{array}$ & & \\
$\begin{array}{l}\text { Präzipitat, berechnet auf die } \\
\text { eingesetzte TCA-AG-Menge }\end{array}$ & $\mathbf{1 0 2}$ & $101-103$ \\
\hline
\end{tabular}

Tab. 4. Bilanz der ${ }^{131} \mathrm{~J}$-Humanalbumin-Versuche mit AntigenAntikörper-Präzipitation und nachfolgender TCA-Ac-Extraktion. Eingesetzte AG-Radioaktivität $=100 \%$ gesetzt.

Dagegen blieben bei der zweiten AG-AK-Reaktion bei Antikörperüberschuß, also nach der TCA Ac-Extraktion des ersten AG-AK-Präzipitats, weniger als $1 \%$ dieses immunologisch und mit TCA Ac gereinigten ${ }^{131} \mathrm{~J}-\mathrm{HSA}$ - AG in den Überständen gelöst. Dies bedeutet eine spezifische und praktisch vollständige AK-Präzipitation eines AG. Die in den Überständen gefundenen Werte sind absolut verläßlich, da hier direkte Messungen in Fiolaxgläschen ohne vorausgehende Verdünnungen durchgeführt wurden, so daß Pipettenfehler und Fehlermultiplikationen nicht in Frage kommen.

16 M. Heidelberger, F. E. Kendall u. T. Teorell, J. exp. Medicine 63, 819 [1936] ; M. Heidelberger u. F. E. KenDALL, J. exp. Medicine 64, 161 [1936].

17 H. Friedrich-FreKSA, persönl. Mitteilung.

18 G. Ramon, C. R. Soc. Biol. 88, 167 [1923]; C. R. Séances [Doklady], Acad. Sci. URSS Filiales 176, 267 [1923], zit. nach H. Sснмidt, Fortschritte der Serologie, Verl. Steinkopff, Darmstadt 1955.

\section{Diskussion}

Vor Schwert ${ }^{2}$ haben bereits Levine ${ }^{4}$ sowie DelavILLE $^{5}$ beobachtet, daß TCA-Präzipitate von HSA bzw. Rinderalbumin in polaren Lösungsmitteln löslich sind. Nahezu gleichzeitig mit Schwert haben Korner und Debro ${ }^{6}$ die Verwendung von TCA. Äthanol für die Herstellung von Albumin empfohlen. Alle diese Autoren fanden, daß nur die TCA-Fällung von Albuminen reversibel ist, während Globuline nach einer TCA-Fällung nicht mehr in Lösung gehen. Nach unseren Befunden werden jedoch nach einer Neutralisierung der TCA mit $\mathrm{NaHCO}_{3}$ außer den gesamten Albuminen auch gefällte $\alpha$ - und $\beta$-Globuline teilweise wieder löslich. Durch TCA werden also bei saurem $p_{\mathrm{H}}$ offensichtlich nur $\gamma$-Globuline vollständig und irreversibel gefällt. Dagegen ist die Irreversibilität der $\alpha$ - und $\beta$-Globulinfällung beim TCA - Ac-Extraktions-Verfahren in erster Linie dem Ac zuzuschreiben, während Albumine durch die Anwesenheit von TCA im Sinne von Schwert spezifisch gegen die Ac- oder Alkohol-Fällung bei Zimmertemperatur geschützt werden.

Die genannten Autoren ${ }^{2,4-6}$ stimmen darin überein, daß Albumine durch eine TCA-Behandlung ihre wesentlichen physikalisch-chemischen Eigenschaften nicht verlieren. Unsere Befunde über die papierelektrophoretische Beweglichkeit, das Farbstoff-Bindungsvermögen und die immunologischen Eigenschaften von TCA-HSA ergänzen diese Untersuchungen; die einfache TCA - Ac-Methode ist demnach zur Herstellung von biologisch einwandfreien, hochgereinigten Albuminen geeignet.

Darüber hinaus ist bemerkenswert, daß sich durch eine TCA - Ac-Behandlung ein Protein-AG, nämlich HSA, aus einem AK-Präzipitat extrahieren läßt. Es ist zwar seit langem bekannt, daß verschiedene $A K$ Präzipitate oder Agglutinate von Antigenen ohne definierten Proteincharakter (z. B. Bakterien, Pneumokokken-Polysaccharide ${ }^{16}$, auch Tabakmosaikvirus ${ }^{17}$ ) mit Hilfe von Essigsäure ${ }^{17,18}$ oder Salzlösungen ${ }^{16}$ getrennt werden können; ferner wurden für solche Zwecke Proteasen ${ }^{19}$ oder verdünnte Alkalien $^{20}$ verwandt. Abgesehen von Diphtherietoxi-

19 M. L. Petermann u. A. M. Pappenheimer, J. Phys. Chem. 45, 1 [1941] ; C. G. Pope, Brit. J. exp. Pathol. 20, 132, 201 [1939].

20 S. C. Luv u. H. $W_{U}$, Chin. J. Physiol. 25, 465 [1942], zit. n. l. c. ${ }^{22}$. 
nen ${ }^{18,19,21}$ und Ovalbumin 20 ist uns jedoch über eine befriedigende Trennung von präzipitierten Protein-Antiproteinsystemen bisher nichts bekannt geworden. Die TCA - Ac-Extraktion stellt also nach unseren Versuchen eine weitere brauchbare Methode zur Rückgewinnung von löslichem und immunologisch unversehrtem Albumin-AG aus AK-Präzipitaten dar.

\section{Methodik}

\section{TCA-Ac-Extraktion von Seren}

Die Proteinlösungen wurden genau nach der Vorschrift von Schwert ${ }^{2}$ mit gleichen Volumina 10-proz. TCA gefällt, die Präzipitate sofort abzentrifugiert, mit 80-proz. Ac extrahiert, nochmals abzentrifugiert, und die albuminhaltigen Überstände gegen $\mathrm{H}_{2} \mathrm{O}$ ausdialysiert. Aus den dialysierten und notfalls anschließend zentrifugierten Extrakten wurden aliquote Teile für die N-Bestimmung nach $\mathrm{K}$ j e l d a h l entnommen. Vor der Papierelektrophorese wurden die Extrakte durch Pervaporation eingeengt, wobei allerdings durch Eintrocknen von Proteinen an der Innenseite der Dialysiermembran Verluste von $10-40 \%$ entstanden; die Denaturierung durch Trocknung ist um so umfangreicher, je mehr $\mathrm{H}_{2} \mathrm{O}$ abgedampft wird.

2. TCA-Fällung mit nachfolgender $\mathrm{Neutr}$ alis a tion

Jeweils $10 \mathrm{~cm}^{3}$ Humanserum wurden mit $10 \mathrm{~cm}^{3}$ 10-proz. TCA versetzt. Das abzentrifugierte Präzipitat wurde in $10 \mathrm{~cm}^{3} \mathrm{H}_{2} \mathrm{O}$ suspendiert und mit ca. $250 \mathrm{mg}$ $\mathrm{NaHCO}_{3}$ (wegen der $\mathrm{CO}_{2}$-Schaumbildung vorsichtig etappenweise) neutralisiert. Die neutralisierte Lösung wurde bei $20000 \mathrm{~g}$ klar abzentrifugiert. Weitere Verarbeitung wie unter 1. nach der Ac-Extraktion beschrieben, jedoch Dialyse gegen Tyrodelösung ohne Glucose.

\section{F a r b t of f-Bind ungsversuche}

Es wurde Bromphenolblau (Tetrabromphenolsulfophthalein, E. Merck, Darmstadt) verwendet. Die „klassischen" Gleichgewichtsdialysen wurden durchgeführt wie bei l. c. ${ }^{12}$ beschrieben. Details dieser Methode und der „Konkurrenz"-Dialysen werden a. a. O. ${ }^{8}$ beschrieben werden.

\section{Immunologis che Versuche}

Zur Erzeugung von Antiseren gegen hochgereinigtes und elektrophoretisch geprüftes HSA (Behring) und gegen das aus diesem gewonnene TCA-Albumin wurden jeweils mehrere Kaninchen immunisiert. Jedes Tier erhielt $150 \mathrm{mg}$ Protein als alaunpräzipitiertes ${ }^{22} \mathrm{AG}$

21 C. G. Pope, Brit. J. exp. Pathol. 38, 207 [1957].

22 E. A. Kabat u. M. M. MaYer, Experimental Immunochemistry, Springfield 1948. innerhalb 4 Wochen, auf 15 i. v. Injektionen verteilt, gespritzt. Wir entbluteten die Tiere 6 Tage nach der letzten Injektion. Die quantitative Präzipitationsreaktion mit den besten Antiseren führten wir nach der Technik von Heidelberger und Kendall ${ }^{23}$ durch; die Ansätze enthielten je $1,5 \mathrm{~cm}^{3}$ Antiserum, und $\mathrm{AG}$ in steigender Menge in 1,5 $\mathrm{cm}^{3}$ gepufferter 0,9-proz. NaCl-Lösung, $p_{\mathrm{H}}$ 7,2. Nach 24 Stdn. wurden die Präzipitate dreimal in 0,9-proz. NaCl-Lösung gewaschen und vor der Stickstoffbestimmung in 1-n. $\mathrm{NaOH}$ gelöst. Die Überstände prüften wir qualitativ auf $\mathrm{AG}$ und $\mathrm{AK}$.

$$
\begin{aligned}
& \text { 5. T.CA-Ac-Extraktion d e r } \\
& \text { 131 J-A G-AK-Präzipitat e }
\end{aligned}
$$

Für unsere 2 ersten Versuche wurden je $1,12 \mathrm{mg}$ $=15,4 \mu \mathrm{C}{ }^{131} \mathrm{~J}-\mathrm{RISA}$ (Abbott Lab., Chicago), für die 3 letzten Versuche je $1,5 \mathrm{mg}=4,3 \mu \mathrm{C}{ }^{131} \mathrm{~J}-\mathrm{HSA}$ eigener Herstellung ${ }^{24}$ mit Kaninchen-AntihumanalbuminSerum von hohem AK-Titer im Äquivalenzbereich präzipitiert. Die AG-AK-Präzipitate wurden 5- bis 10-mal mit je $3 \mathrm{~cm}^{3}$ 0,9-proz. NaCl-Lösung gewaschen, mit $0,05 \mathrm{~cm}^{3} \mathrm{H}_{2} \mathrm{O}$ und $0,25 \mathrm{~cm}^{3} 10$-proz. TCA versetzt, aufgerührt und abzentrifugiert, danach in $0,1 \mathrm{~cm}^{3} \mathrm{H}_{2} \mathrm{O}$ und $0,4 \mathrm{~cm}^{3} \mathrm{Ac}$ aufgeschlämmt und abzentrifugiert. Die Überstände dialysierten $48-72 \mathrm{Stdn}$. gegen $\mathrm{H}_{2} \mathrm{O}$; die Präzipitate wurden $1-2$-mal in 5-proz. TCA resuspendiert, zentrifugiert und mit $0,5 \mathrm{~cm}^{3} 80$-proz. Ac extrahiert; diese zweiten oder dritten Extrakte dialysierten gemeinsam mit den ersten.

Bei 2 Versuchen entnahmen wir erst nach der Pervaporation einen aliquoten Teil von $0,1 \mathrm{~cm}^{3}$ zur Radioaktivitätsmessung, bei 3 späteren Versuchen schon vor der Pervaporation.

Mit den pervaporierten Extrakten führten wir $\mathrm{Pa}$ pierelektrophoresen durch. Zwei nicht-pervaporierte Extrakte wurden nochmals mit der berechneten Menge AK versetzt, und die Radioaktivität der 3-mal mit je $3 \mathrm{~cm}^{3}$ 0,9-proz. NaCl-Lösung gewaschenen Präzipitate sowie der Überstände gemessen.

Zur Messung der Radioaktivitäten (jeweils mindestens 20000 Impulse) benutzten wir einen Szintillationsbohrloch-Kristall (Frieseke \& Höpfner, Erlangen) und Fiolaxgläschen (Schott \& Gen., Mainz).

6. Die Technik der Papierelektrophoresen und A utoradiographien ben.

Diese Verfahren sind in der Arbeit 1. c. ${ }^{24}$ beschrie-

Einen Teil der Versuche führten wir im Rahmen von Arbeiten durch, die von der Deutschen For$\mathrm{schung} \mathrm{s}$ gemeins chaf $\mathrm{t}$ und von einer Stiftung der Rober t B os c h G m b H., Stuttgart, unterstützt werden. Frl. Rodenwaldt und Frl. Steitz danken wir für die technische Assistenz.

23 M. Heidelberger u. F. E. Kendall, J. exp. Medicine 61, 563, [1935]; 62, 697, [1936].

24 E. Kallee u. G. Seybold, Z. Naturforschg. 9 b, 307 [1954]. 